\title{
Between the Household: Researching Community \\ Organisation and Networks
}

\section{Sue Fleming}

\section{Introduction}

The World Bank has come a long way in appreciating the micro-dimensions to structural adjustment. Although there are still analyses limited to macroeconomic reform [Selowsky 1987; World Bank/UNDP 1989] much of the recent literature has taken a wider view. This micro-focus has concentrated on measuring the impact of adjustment through the "creation of statistical data bases to assess the way living conditions of households evolve' [World Bank $1989 \mathrm{c}: 188$ ] with the aim of 'linking the analysis to the design of compensatory programmes to mitigate the impact of adjustment on distressed groups' [World Bank 1989c:207]. At the same time growing attention has been paid to community organisations and networks, first as an answer to poverty alleviation and later as providers of sustainable development.

The initial emphasis on community and NGOs was on filling gaps in the social sector, due to the shrinking government role in structural adjustment. Poverty focused World Bank programmes were designed to make 'extensive use . . . of community initiative projects and NGOs' [World Bank 1988:49]. Housed in the concept of "promoting local self-reliance ... the main aim would be to mobilise local energies to provide local services' [World Bank 1989c:188]. Such policies are also in line with UNICEF proposals to use a less skill-intensive and more community-based approach to the delivery of social services, for example instituting a primary health system with 'Village Health Volunteers and para-professionals with the ability to treat common ailments' [Cornia, Jolly and Stewart 1987:176]. Aside from the more generally obvious resource constraints, such self-help policies have been criticised for the increased demands they place on women's already over utilised time [Antrobus 1988; Elson 1988].

Community organisations have also been given a role in providing informal finance. A full chapter of the 1989 World Development Report devoted to the subject concluded that 'most of the financial needs of the non-corporate sector are met quite well by a wide variety of informal arrangements' [World Bank 1989: 121]. There is also talk of mobilising 'community savings ... not only to finance development needs but also to generate productive employment' [World
Bank 1989c:169]. Community organisations could be targets for extension and credit, 'women's groups need to be fostered. They could then be used, for instance, not only as contacts for extension services but also for channelling credit for the purchase of inputs' [World Bank 1989c:104].

For the World Bank, community participation is the key to these actions. 'Communities must be consulted and encouraged to participate in setting their own priorities and in the design and delivery of health care programs'. [World Bank 1989c:65]. The SDA project strategies include 'fostering the participation of the poor in socioeconomic activity, in particular by promoting community-level initiatives aimed at smallscale, income generating activities and small-scale, social infrastructure' [World Bank 1989c: 188].

Participation for the 90 s emphasises community's decision-making role. A 'major challenge' of the SDA project 'will be to promote the participation of community groups and NGOs in designing and implementing socioeconomic policies and development plans [World Bank 1989c:188]. Although in practical terms community policymaking is still discussed in the context of self-reliance and linked to community resourcing and management. UNICEF similarly regards community participation as critical 'in helping to formulate policy, in providing the administrative mechanisms for aspects of the programme, such as community feeding schemes ... and in providing resources of labour and food to pay for some basic services' [Cornia, Jolly and Stewart 1987:139]. Such participation helps 'to improve the design of policies so that they correspond to the needs and conditions of the people to whom they are directed; and to improve the efficiency of the policies in terms of their objectives [Cornia, Jolly and Stewart 1987:163] (author's emphasis).

The political dimensions of community participation are being more loudly articulated. For UNICEF 'empowerment and participation of vulnerable groups, especially women, helps to secure the political commitment to get the policies introduced and effectively implemented [Cornia, Jolly and Stewart 1987:163] it provides 'strong political support for adjustment with a human face which will help counter potential opposition of other interests' [Cornia, Jolly and Stewart 1987:139]. The African Alternative 
Framework to Structural Adjustment Programmes takes a more macro-political view, and calls for 'broad participation in decision-making', 'greater accountability', 'local decentralisation' and 'democratisation' (United Nations Economic Commission for Africa 1989).

The World Bank refers to 'better governance' and 'political renewal' through 'empowering' local people such as "women and the poor through grassroots and non-governmental organisations' [World Bank 1989c]. 'Every opportunity should be taken to support local, communal and non-governmental organisations of all types ... the challenge is to build on this solid indigenous base, with a bottom-up approach that places a premium on listening to people and on genuinely empowering the intended beneficiaries of any development programme'. [World Bank 1989c: 191] Improved democracy is being linked to donor conditionality, and limits put on external aid' . . . unless governance in Africa improves. Leaders must be more accountable to their peoples' [World Bank 1989b:15] (author's emphasis).

Given the increasing political, social and economic importance attributed to these organisations it is surprising that they are regarded as unproblematic. Neither the World Bank, nor UNICEF nor UNECA, all of whom promote these groups, have assessed their differing relevance, or at least made any clear distinctions between them. A homogeneity is assumed although the range of these community and nongovernment organisations is considerable. For the World Bank they include groups "for land management, for cooperative marketing and input supply, for savings and credit' [World Bank 1989c:60] 'village associations, cooperatives, credit unions, professional associations, chambers of commerce and industry ... [World Bank 1989c: 191].

The commendable aim of community participation in policy formulation is still isolated from other policy components - notably 'the design and implementation of both macromodelling frameworks .... and core social expenditure programmes' as well as 'strengthening government capacity for social policy planning and programming, policy analysis of the social dimensions of adjustment, and creation of statistical data bases' [World Bank 1989c:188]. At present there is no method for integrating community generated policy into these national systems or adapting current macro-policymaking to the proposed bottom-up approach.

This paper stresses the variety of these community groups and networks, and the problems this holds for a gender aware and participatory development. It argues for research and analysis that takes account of these community groups and networks, realising the limits to current micro-level household data for structural adjustment policy. It puts forward ideas for action research and analysis, with appropriate community groups, that integrate a policy-making role, having outlined some of the problems in linking this to macro-policy.

\section{What are these community organisations?}

As the workshop is concerned with household arrangements it is useful to begin the descriptions of community organisation with that of the household. 'In much of the anthropological literature, 'household' is the term used to refer to the basic unit of society involved in production, reproduction, consumption and socialization' [Moore 1989:54], with variations across cultures and history and a base in local definitions. In statistics it usually refers to "people living together under one roof, eating from one kitchen and sharing a common budget' [United Nations 1988:46], a point debated by others in this volume. The variety of community organisations and networks represent other loci of cooperation, other units of consumption, production, accumulation and distribution, including the "various forms of cooperation and collectivity in domestic work between households' [Harris 1981:63].

The variations in relations within and between households have led to questioning "whether the household is the most satisfactory unit of analysis. Feminist critics have argued that an overemphasis on the bounded household leads to a misleading conceptualization of households as autonomous units, where marriage is the defining relationship between the genders and conjugal relations are privileged over other types of relations and strategies'. [Moore 1989:59].

The most well known inter-household linkages are those of kinship [Guyers and Peters 1987] illustrated through 'nesting' units; households within compounds situated within extended family units of increasing scale. Less publicised organisation is based on a range of other ties such as locality, age, interest, and economic activity. These cover neighbourhood groups, peer (including old boy) networks, women's groups, church and ritual organisations, shared labour groups and peasant associations [March and Taqqu 1986].

These organisations are important for resource allocation [Whitehead 1984]. They are concerned with welfare, and food can be re-distributed through these networks. Communal kitchens [ECLAC 1988] can reduce both cost and labour of household provisioning and have been one of the survival responses to structural adjustment programmes. There are endless examples of organisation of childcare, from Club de Madres in Latin America, baby-sitting networks in Manchester to kindy's in Ysabel, Solomon Islands.

Inter-household organisations also form the basis of 
directly economic activities. Land can be collectively owned, either through some form of association or cooperative, or through more traditional kin-based land holding groups. Decisions on land allocation and use are made through these groups. Attempts to bypass these groups in the Solomon Islands has led to long-term difficulties for governments and foreign investers; a Levers logging camp was burnt down as the company had begun extracting timber without the land-holding group's agreement.

Labour is often collectively organised. The work groups may be seasonal, a means of obtaining labour at peak demand. The women in Adidwan, Ghana, who collectively de-husk each others' maize ready for milling, provide a good example. Labour intensive tasks such as housebuilding can be carried out by a wider group on a more ad hoc basis. Collective labour can also be continual, such as the women's weaving groups in Tonga, who work a 20-40 hour week together spending a day at a time on each member's weaving.

Ownership of the goods and services produced by these organisations can also be collective. In this case the property, or benefits, would either belong to the group, or be distributed to individual members. The women's dairying cooperatives in Moshi, Tanzania, and the Peasant Association in Boane, Mozambique are more formalised examples where benefits accrue to individuals. On the other hand, collective production generated under the umbrella of the church, village, peasant or village group would include some support for group based personnel and activities.

Other organisations, such as the mutual aid societies, are concerned with capital flows; with saving, credit, insurance and investment activities [Okorie and Obeta 1986]. Marketing and trade operate within informal associations and networks that can set prices and conditions [Berry 1986].

Organisations and networks also form around issues. These include urban groups, whose demands may centre around education, health, and consumer/price concerns [UNICEF 1987]. It also includes social movements campaigning, for example, for legislation concerning violence against women, for day care, housing and human rights [ECLAC 1988].

\section{Gender Dimensions}

There are obvious gender dimensions to sex specific groups and networks. Development Alternatives with Women for a New Era (DAWN)'s central strategy is 'empowering ourselves through organization'. This strategy recognises differences between the widely varying women's organisations, and addresses the preconditions for this empowerment.

DAWN have identified six major forms of women's organisation as well as women's movements centred around basic needs and issues. These are traditional service oriented organisations, those affiliated to political parties, to projects, as well as worker based, grass roots, and lastly research organisations. The necessary conditions for 'empowerment of organisations, individuals and movements' include 'open and democratic processes' with 'shared responsibility and decision-making' [Sen and Grown 1988:89].

For Moser [1989] 'Third World women's organisations form a continuum from those whose purpose is direct political action, those exchanging research and information, to the traditional, service-oriented organisations' [Moser 1989a:1816]. The 'empowerment approach' seeks to assist the more traditional organisations to move toward a greater awareness of feminist issues [Moser 1989a:1816].

Community groups are given only a brief mention in these discussions of organisational typology and change. Moser refers to the need for external intervention to realise the necessary transformation in these groups; it is the 'empowerment approach' of larger organisations which 'seeks through bottom-up women's organisations to raise women's consciousness to challenge their subordination' [Moser 1989a: 1816]. DAWN, although aware of local and participatory women's groups, use their category of grassroots organisations to refer to those who 'direct their work to poor and working women' [Sen and Grown 1988:92]; the differing attributes of the local level groups are not dealt with.

March and Taqqu in their work on informal women's associations, have come up with categories for defining these micro-level groups, but conclude that only equitable associations 'in which economic resources are acquired and/or organized' [March and Taqqu 1986:46] have development potential. Unlike Moser and DAWN, they do not see a more general capacity for transformation through inter-organisational links; either consciousness raising interventions [Moser 1989a] or 'mutual education' between research groups and other types of women's organisation [Sen and Grown 1988]. The practice lies between two positions; there is a realistic note of doubt in DAWN's promotion of 'coalitions and alliances (possibly across different women's organisations and political affiliations)' as a strategy for political action and support on women's issues [Sen and Grown 1988:87] it is certain that characteristics such as homogeneity in an organisation's membership promote mutual interest and participation, and have been one of the reasons for separate women's groups, and the newer young women's groups.

The gender and development issues discussed so far have been directly concerned with political aspects of women's organisations, focusing on participation as a crucial factor. It is important to extend the debate to 
include the range of mixed male/female organisations as they also impinge differently on women and men's ability to think, talk and act; they influence, and hence help to define, gender roles.

For example, women in British households and families are known as 'housewives'; cooks, cleaners, household managers and child carers. The Kindy's in Ysabel focus on women's child caring role. Women cooperative smallholders in Arusha are firstly dairy farmers, in the workgroups in Angola they are agriculturalists, in Tonga weavers. As participants in Tongan village meetings women are food organisers, in the water committee they are administrators and community managers. A man's role is different in the work place, in the family, and in the bar, pub or kava club with his mates.

Each organisational context provides a different forum for debate, it permits or limits the content of discussion and relations between members. Decisions of a water committee are different to those within the household. Women on the committee address community management concerns at village level, they may in the process legitimize new areas of women's activities, and also use the committee as a public platform for household level debates.

The constraints and possibilities that organisations impose on individuals have serious consequences for research method. The standard data gathering method for development planning is the household survey, which captures, and hence emphasises the role of individual members in that particular context. As pointed out by Moore [1988], the household implies the priority of marriage over other relations. Women are classified according to husbands (present, absent or dead), and their activities viewed in relation to the totality of the household. But brothers, resident elsewhere, could be more significant for access to land; mothers for childcare; female neighbours for food security. Activities may be carried out in the context of a creche, of the church, of a women's group, for the support of that group.

Information from the household reflects the divisions of labour and responsibilities in that environment. This information is filtered through social norms governing what can and cannot be said in the household/family context. There are topics that cannot be touched on when both men and women are present, that cannot be articulated by a husband about his wife and vice-versa, that cannot be mentioned in front of unmarried women. The conversations between men in the kava clubs would not occur in front of their wives. Research on women's work in Tonga, drawing on data from different research strategies, showed up discrepencies between the stories presented through household gathered data, and that collected through the women's weaving groups [Fleming 1986].
Participation, Empowerment and Democracy

It is clear from the discussion of gender dimensions that a central difference between organisations concerns questions of participation, empowerment and democracy. These differences are not academic. They are realised in the very tangible problems that national organisations are faced with in linking the policy of participation with practice.

There are a set of issues that relate primarily to improving representation of individual members within the organisation. Rural women's involvement in the Organisation of Angolan Women, is through village-level assemblies, who are then represented at municipal, then provincial and finally national level. Their activities to date have essentially been directed from above. Changing attitudes about local level participation have resulted in talk of sub-groups in the villages; these smaller groups would make it easier for women to talk and act together.

The issue of representation also brings in questions of legitimacy. To what extent does the organisation as a whole stand for the interests of its members, not only in terms of internal democracy but how it links into other organisational structures, and is viewed from the outside. The formation, in Mozambique, of local NGOs that could be seen to represent women such as the National Union of Cooperatives, the new Community Development Foundation and the Office for the First Lady has led to confusion. Who 'represents' Mozambican women, these new 'women's' NGOs or the Organisation of Mozambican Women?

The Union of Peasant Associations in Angola, formed in February 1990, faces credibility in the extent to which it 'represents' the interests of its members. Although created through a series of municipal, provincial and finally national level meetings, i.e. from the 'bottom-up', the 'orientation' or direction came from the party's central structures, and there seem to be bottlenecks in information flow from the ground. The major concern of the more local level assemblies, agricultural and consumer prices, was not addressed at national level as it was not on the nationally set agenda.

Individual peasant associations are not necessarily democratic structures, as illustrated by the position of women farmers. Firstly, women farmers are not always members. The rules of some associations allow only one representative per household, the "household head'. In these cases widows, divorced and separated women have a voice as female household heads; married or attached women may attend but without an official status. Secondly even if women attend as fully fledged members, they may not be in a position to participate on an equal basis to men. In one association meeting the women asked for time on their 
own so they could discuss their response, which was then communicated through a spokeswoman to the wider meeting.

The issues surrounding membership rights and separate interests of women have been discussed in 1988 the context of multi-purpose cooperatives in Tanzania. To set the scene; women dairy farmers in the Mount Kilimanjaro area wanted to register themselves as a dairy cooperative, but the rules allowed for only one (multi-purpose) cooperative per village. The village level cooperative, as with the umbrella organisation, Kilimanjaro Native Cooperative Union, was dominated by coffee production, firmly in the hands of men.

There are a number of questions that arise from this scenario. Do the women continue as a separate group, in control of their dairying activities, but without legal status and the access to credit and other resources that this status brings? Do the women enter the multipurpose cooperative as (dairy) producers in their own right, in perhaps a dairying 'section' but with overall control by male 'coffee' interests? Should there be reform of the cooperative structure to allow for more than one cooperative in each village, and allowing for a dairying cooperative union?

The balancing act of enabling women to control their separate (dairying) interests is complicated by the wider political role of multipurpose cooperatives in Tanzania. Would women's membership of these cooperatives, as independent economic agents, integrate women into wider decisions in the village, including those about coffee? Given women's difficulties in contributing to this essentially male grouping, when is a women-only forum needed, and how could it be most effectively linked in to this multipurpose and potentially gendered cooperative? Is more than one women-only grouping required to take account of the inhibitions poorer and less articulate women may have within a less homogenous group?

There is obviously a complexity and specificity to 'participation' that varies between organisations. This has importance not only at the local community level, but for the meso and macro organisations that provide national level links. World Bank, UNICEF and UNECA intentions to consult the community and build community participation into structural adjustment policy formulation raises problems at all these levels, particularly if empowerment and democratisation are serious objectives.

The issue returns again to the question of defining democratic structures and the conditions that enable participation; developing criteria that should be present in discussions of both community involvement and the interconnecting mechanisms that provide macro-level links. DAWN's 'requisites' for empowerment provide a useful starting point for further work: 'These include resources (finance, knowledge, technology), skills training, and leadership formation on the one side; and democratic processes, dialogue, participation in policy and decision-making, and techniques for conflict resolution on the other'. 'Within organisations, open and democratic processes are essential . . . the long-term viability of the organization, and the growing autonomy and control by poor women over their lives, are linked through the organization's own internal processes of shared responsibility and decision-making, [Sen and Grown 1988:89].

Including external resources and policy participation as a precondition raises a series of policy issues that the World Bank has only begun to address in its structural adjustment programmes. How is 'democratic' 'bottom-up' policy going to feed into national/international macro policy making? On a more topical note, how is the obvious popular participation manifest in the recent riots in Zambia going to effect the structural adjustment policies in that country? The World Bank answer to external resourcing is NGOs. 'NGO support structures should be encouraged to serve as a link between the state and thousands of small self-help and community development efforts' [World Bank 1989c: 169]. NGOs are 'cost conscious', and this 'efficiency' is one of their attractions as they 'put together projects with minimal financial and external technical assistance' [World Bank 1989c:183].

Another important justification for NGO involvement is the quality of the link they have with the community. 'NGOs have learnt how to work with grassroots organisations' [World Bank 1989c: 183] and are 'closer than the government to the rural communities', 'they develop an empathy that government staff generally lack' [World Bank 1989c:169]. But what is the nature of this empathy? Is it based on democratic processes, dialogue and participation? If NGOs then form a part of democratisation how do they fit into national policy-making?

The World Bank sees an advocacy role for indigenous NGOs who are 'both intermediaries and advocates for their grassroots constituencies' [World Bank $1989 \mathrm{c}: 142]$. But in practice this role has only been allocated to 'associations of small-scale entrepreneurs' and farmers associations. The former have been viewed in the same light as chambers of commerce; are informal, operate through 'consensual decisionmaking' and would represent the interests of smallscale enterprises, improve access to capital and information and identify resource needs [World Bank 1989c: 142]. Farmers associations are a mechanism for pressurising the 'political and economic elite', and there is at last a realisation by the World Bank that they need to be democratically structured. 'These, if genuinely representative, constitute a step toward empowering local people'. [World Bank 1989c:103] (author's emphasis). 
Wider political implications of the advocacy role NGOs could take vis-a-vis the state are brushed aside. For NGOs "critical of government policies, especially when these are seen as hurting the disadvantaged . . . an element of tolerance by the government would be desirable' [World Bank 1989c: 182]. This criticism is a 'problem of success' that requires 'time to resolve'. But at the same time 'this calls for caution, and money should not be thrown blindly at institutions, projects and programs'. [World Bank 1989c: 182].

'Genuine empowerment' and participation in socioeconomic policy design [World Bank 1989c] cannot be dependent on pressure group politics, and the whims of project funding. If the World Bank and Governments are serious about democratisation, structures and information systems are needed that would enable the creation of policy from below to effect the necessary change in macro-policy. Effecting participation in socio-economic policy design [World Bank 1989c] means removing the barriers to this inherent in existing methods of policy formulation [Fleming 1991]. Information alone is not sufficient for macro policymakers to integrate bottom-up directives, there also needs to be political commitment to ensure that it takes place.

\section{Improving Policy/Action Information Systems}

There are two aspects to data gaps in the current information gathering system. One relates to content, and it is clear that there has been insufficient systematic attention to community organisation, that the existing typologies developed by feminist researchers need to be expanded to include mixed male/female groups, and that they need to be further linked to development criteria, with elaboration of distinctions between the capacity and the potential to transform - organisational culture [Conyers 1989], homogeneity and economic independence all obviously playing a part. The dynamic of participation both within and between organisations needs to be better understood, particularly as community organisations have been heralded as future 'democratic' building blocks of society.

The SDA project has responded with the idea of a community survey. But there is a danger that community groups, as with the household, will be viewed as bounded units. The dynamic and quality of intra and inter-organisational relationships will then be lost, particularly if this information is to be collected purely through the medium of a statistical survey for national level analysis.

The second dimension relates to the process of information gathering and policy analysis and the dynamic between information, analysis and transformation. Both community level policy creation and the influence of the organisational framework on individuals ability to participate needs to be dealt with and this is possible by making the organisation and the people in them explicit, the subjects of research and analysis. Being a subject means involvement in defining the research; integrating local perceptions, categories and priorities. This means dealing directly with local understanding and awareness of change. More to the point such policy research provides a tool for empowerment and institutional development as it becomes a mechanism for analysing and making decisions, of discussing and agreeing on what and how to change including aspects of the institution itself.

DAWN have clearly identified a role for research organisations in empowerment strategies. "These include groups involved in participatory action (and policy) research, women's studies associations, and research networks. Such groups have considerable potential to influence public policy debates, evaluate the programmes of agencies and governments, inform and feed research into other types of women's organisations, and link research with action. These groups aim to eliminate the distinction between the researcher and the researched, so that research becomes a process of mutual education. They are also committed to using their findings to serve and empower the subjects of the research'. [Sen and Grown 1988:92].

Quite rightly DAWN recognise the difficulties of linking these meso/macro level organisations with the community. 'The challenge facing these groups is to develop structures and methods of accountability to both action organizations and the subjects of the research, perhaps through stronger policy linkages or direct services' [Sen and Grown 1988:93].

Links between research and analysis at the point of data collection are essential for this locally determined development process. But they are not a sufficient condition for empowerment. As mentioned earlier the development decisions only have meaning if they link into wider institutions and structures, if they are carried out in the necessary policy environment, and with agencies, both government and NGO, that can follow through with any external resources and information required.

If NGOs and local organisations are the mechanism for community policy creation then requests for government acknowledgement of this role need to be heeded. NGO recommendations for an NGO initiated 'system for institutionalising dialogue between NGOs and government' and 'for involving NGOs in government policy formulation and development planning' [Commonwealth Secretariat 1989:21] need to be taken seriously by both partners provided of course the necessary conditions for empowerment and participation are satisfied. 
Many thanks to Diane Elson for our many discussions and her comments on the draft.

\section{References}

Antrobus, P., 1988, 'Consequences and responses to social and economic deterioration; the experience of the Englishspeaking Caribbean'. Paper for the workshop on Economic Crises, Household Survival Strategies and Women's Work, Cornell University, September 2-5

Berry, S., 1986, 'Macro-policy implications of research on rural households and farming systems in Moock, J. L. (ed.)'. Understanding Africa's rural households and farming systems. Westview, Boulder

Commonwealth Secretariat, 1989, 'Strategic issues in development management; learning from successful experiences', Livingstone, Zambia, 9-13 May

Conyers, D., 1989, 'Summary of conclusions, Strategic issues in development management: learning from successful experiences', Commonwealth Secretariat, London

Cornia, G. A., Jolly, R., Stewart, F., 1987, Adjustment with a human face; protecting the vunerable and promoting growth, Clarendon Press, Oxford

ECLAC, 1988, 'Latin America and Carribbean women between change and crisis'. Working Paper for the UN Interregional seminar on Women and the Economic Crisis, Vienna, Oct. 3-7

Elson, D., 1988, 'From survival strategies to transformation strategies: women's needs and structural adjustment', Paper prepared for the Workshop on Economic Crises, Household Survival Strategies and Women's Work, Program on International Development and Women, Cornell University, September 2-5, 1988

Fleming, S., 1986, 'Women's work and development in Tonga'. Occasional Paper 10. South Pacific Smallholder Project, University of New England, Armidale

-1991, 'Institutional development in World Bank structural adjustment programmes'. Dissertation for MA(Eeon) in Development Studies, Faculty of Economic and Social Studies, University of Manchester

Guyer, J., 1981, 'Household and community in African studies'. African Studies Review' 24, 2/3

-and Peters, P. E., 1987, 'Conceptualising the household; issues of theory, method and application'. Development and Change vol 18 no 2

Harris, O., 1981, 'Households as natural units', in K. Young et al. (ed). Of marriage and the market. CSE Books, London

INSTRAW, 1988, 'Innovative methodologies for research and training'. Working paper, United Nations Interregional Seminar on Women and the Economic Crisis, Vienna, October 1988
Lamb, G., 1987, 'Managing economic policy change institutional dimensions', Discussion Paper 14, World Bank, Washington

March, K. and Taqqu, R. L., 1986, Women's informat associations in developing countries; catalysts for change? Westview, Boulder

Moser, C., 1989a, 'Gender planning in the Third World: meeting practical and strategic gender needs'. World Development vol 17 no 11

$-1989 \mathrm{~b}$, 'The impact of recession and structural adjustment policies at the micro-level: low income women and their households in Guayaquil, Ecuador'. Invisible Adjustment, vol 2, UNICEF

Okorie, A. and Obeta, M. E., 1986, 'Nigerian traditional mutual aid societies and their compatibility with modern cooperatives'. Journal of Rural Cooperation vol 14 no 2

Sen, G. and Grown, C., 1988, Development crises and alternative visions: Third World women's perspectives. Earthscan, London

Serageldin, I., 1988, 'Poverty, adjustment and growth in Africa'. The World Bank, Washington

UNICEF, 1987, The invisible adjustment: poor women and the economic crisis. UNICEF

United Nations, 1988, 'Improving statistics and indicators on women using household surveys. Studies in Methods, Series F no 48. Department of International Economic and Social Affairs, Statistical Office and International Research and Training Institute for the Advancement of Women, United Nations, New York

United Nations Economic Commission for Africa, 1989, 'African Alternative Framework to Structural Adjustment Programmes for socio-economic recovery and transformation (AAF-SAP)', Addis Ababa

Whitehead, A., 1984a, 'Beyond the household? Gender and kinship based resource allocation in a Ghanaian domestic economy'. Draft paper for a workshop on 'Conceptualising the household: theoretical conceptual and methodological issues'. Harvard Institute for International Development. Nov. 2-4

-1984b, 'Men and women, kinship and property: some general issues'. In R. Hirschon (ed.), Women and property, women as property. Croom Helm, London

World Bank, 1989a, 'The Social Dimensions of Structural Adjustment in Sub-Saharan Africa'. Africa Region, SDA Project Unit, Washington

—1989b, 'World Development Report 1989', Oxford University Press, New York

-1989c, 'Sub-Saharan Africa; from crisis to sustainable growth, a long term perspective', Washington 